\title{
Immunohistochemical expression of DNA repair proteins in oral tongue and lower lip squamous cell carcinoma
}

\begin{abstract}
Deborah Gondim Lambert MOREIRA(a) Everton Freitas de MORAIS(a) (i) Hellen Bandeira de Pontes SANTOS(a) Roseana de Almeida FREITAS(a) (i)

(a) Universidade Federal do Rio Grande do Norte - UFRN, Centro de Ciênicas da Saúde, Department of Oral Pathology, Natal, RN, Brazil.
\end{abstract}

Declaration of Interests: The authors certify that they have no commercial or associative interest that represents a conflict of interest in connection with the manuscript.

\section{Corresponding Author:}

Roseana de Almeida Freitas

E-mail: roseanafreitas@hotmail.com

https://doi.org/10.1590/1807-3107bor-2020.vol34.0101

Submitted: December 26, 2019

Accepted for publication: June 15, 2020

Last revision: July 7, 2020
Abstract: The DNA repair system involves genes and proteins that are essential for the maintenance of genome integrity and the consequent control of various cellular processes. Alterations in these genes and proteins play a role in tumor development and progression and might be associated with prognosis. The aims of this study were to analyze the immunoexpression of two DNA repair proteins, XPF and XRCC1, in lower lip squamous cell carcinoma (LLSCC) and oral tongue squamous cell carcinoma (OTSCC), and to investigate possible associations with clinical and histopathological parameters. The immunohistochemical expression of XPF and XRCC1 was analyzed semi-quantitatively in 40 cases each of LLSCC and OTSCC. The chi-squared test or Fisher's exact test, when appropriate, was used to investigate the association between expression of the proteins and clinicopathological characteristics. The cytoplasmic immunoexpression of XPF was high in OTSCC (95\% of the cases analyzed) but low in LLSCC (52.5\%). Among the clinicopathological parameters evaluated, a statistically significant association was observed between high nuclear expression of XRCC1 and the absence of regional lymph node metastasis in patients diagnosed with OTSCC $(\mathrm{p}=0.006)$. The high protein expression of XPF and XRCC1 in OTSCC and LLSCC suggests an important role in the development and progression of these tumors. Our study found an association between high nuclear expression of XRCC1 and the absence of loco-regional metastasis in cases diagnosed as OTSCC, suggesting a role of this protein in tumor progression.

Keywords: Immunohistochemistry; Pathology; Mouth Neoplasms.

\section{Introduction}

Squamous cell carcinoma (SCC) is the most common oral malignant neoplasm that accounts for more than $90 \%$ of cases in the oral cavity ${ }^{1}$ where it can occur at any site. The oral tongue is the most common intraoral site, which is affected in more than $50 \%$ of cases. ${ }^{2}$

Oral tongue squamous cell carcinoma (OTSCC) is the most prevalent oral cancer; a higher incidence is observed between the sixth and seventh decade of life. Smoking is the main etiological factor associated with its development. ${ }^{3}$ Although the epidemiological profile has changed over time, with considerable regional variations, there is still higher 
prevalence of OTSCC among males, as they have greater exposure to risk factors. ${ }^{1,3}$ OTSCC exhibits an aggressive biological behavior and has usually a poorer prognosis when compared to tumors at other sites. ${ }^{4,5,6,7}$ Lower lip squamous cell carcinoma (LLSCC) is more common among male patients above the age of 50 years and solar radiation is the main etiological factor. ${ }^{7}$ LLSCC is usually associated with a good prognosis and low mortality rate. ${ }^{6,7}$

Despite advances in cancer treatment, the survival of patients with oral cancer has remained unchanged over the last three decades. ${ }^{8,9}$ Patient survival depends on conventional prognostic factors used in clinical practice. The most common are clinical staging of the tumor and different histological grading systems. Although efficient, these factors require complementary methods for analysis of the development, progression, and prognosis of SCC. ${ }^{10}$ Within this context, prognostic biological markers are needed that better reflect the diversity of SCC and that more accurately predict clinical outcomes and responses to certain types of adjuvant therapy. ${ }^{8}$

Carcinogenic agents can trigger the accumulation of genetic alterations, including changes in the normal functions of proto-oncogenes and tumor suppressor genes that affect the cell cycle, immunity and cell differentiation, proliferation and death, as well as modifications in DNA repair. ${ }^{11,12,13}$ The DNA repair system plays a fundamental role in the protection of the genome against endogenous and exogenous agents, preventing cells altered by carcinogens from continuing the cell cycle and their inappropriate proliferation. ${ }^{13,14}$

DNA repair proteins play an important role in different pathways involved in the maintenance of DNA structure and function and might be associated with the clinical prognosis of patients. ${ }^{13,15}$ Human $\mathrm{X}$-ray repair cross-complementing 1 (XRCC1) is the first mammalian DNA repair gene isolated that affects cell sensitivity to ionizing radiation. XRCC1 participates in base excision repair (BER) and single-strand break repair (SSBR) to eliminate the DNA damage induced by chemical mutagens and ionizing radiation. ${ }^{16} \mathrm{XPF}$ partners with ERCC1 to form a bi-partite nuclease that is essential for nucleotide excision repair (NER). ${ }^{17,18}$ XPF-ERCC1 heterodimer is directed to the damaged strand by RPA (replication protein A) to create an incision $5^{\prime}$ to the lesion and remove the single-stranded nucleotide through XPG activation. ${ }^{18,19}$

Studies indicate that the expression of these proteins is deregulated in various neoplastic processes, including SCC; however, the role of these proteins in the biological behavior of OTSCC and LLSCC remains controversial. ${ }^{3,20}$ In this context, studies analyzing the role of the DNA repair proteins XRCC1 and XPF in OTSCC are scarce and, so far, no study has evaluated their immunoexpression in LLSCC. 3,21,22

The objective of the present study was to investigate possible associations of the two DNA repair proteins XPF and XRCC1 with clinical and histopathological parameters in OTSCC and LLSCC, analyzing the role of these proteins in the two neoplastic processes that differ in terms of etiological factors, biological behavior, and prognosis.

\section{Methodology}

This was an observational, analytical, crosssectional study that compared clinicopathological and immunohistochemical characteristics of a sample of cases diagnosed as OTSCC and LLSCC. The study was approved by the Research Ethics Committee of the Federal University of Rio Grande do Norte (UFRN) and was conducted in accordance with Resolution 466/12 of the National Health Council (protocol no. 2.332.567). The informed consent was explained, and the signed approval was obtained from all the participants.

\section{Sample}

Among the OTSCC and LLSCC cases diagnosed between 2000 and 2012 at the Pathological Anatomy Service of the Department of Dentistry, UFRN, cases whose clinical records contained information about clinical stage, treatment, and follow-up were selected by convenience sampling to evaluate the recurrence and death rates of the patients. Only cases whose paraffin-embedded material was sufficient for immunohistochemical analysis were selected. Patients submitted to radiotherapy, 
chemotherapy, or any other treatment before surgery were excluded. Patients with incomplete data regarding patient gender/age, tumor size/ extent, presence of regional lymph node metastasis and distant metastasis, and clinical stage were also excluded. In addition, cases of recurrence and cases of squamous cell carcinoma of the tongue base (posterior one-third), a site belonging to the oropharynx, were not included.

Thus, 40 cases of LLSCC and 40 cases of OTSCC were selected and clinical data including patient sex and age, sun exposure, smoking, alcohol drinking, tumor size, metastasis, recurrence, and outcome were collected. Surgical specimens of the selected cases fixed in formaldehyde $10 \%$, included in paraffin were evaluated by histopathological and immunohistochemical analyses.

\section{Histopathological analysis}

For this analysis, histological sections stained with hematoxylin and eosin were evaluated using the histological grading systems of malignancy proposed by Brandwein-Gensler et al. ${ }^{23}$ and Almangush et al. ${ }^{24}$ Three previously calibrated examiners performed these assessments. Cases where examiners disagreed were resolved by consensus.

For the Brandwein-Gensler grading system, ${ }^{23}$ the worst pattern of invasion, lymphocytic infiltrate, and perineural invasion were evaluated. The scores obtained for each parameter were summed to give a final score of malignancy for each case. Tumors with a final score of 0 were classified as low-risk, those with a final score of 1 or 2 as intermediate-risk, and those with a final score 3 as high-risk.

The cut-off point for tumor budding was set at five buds (low $<5$; high $\geq 5$ ), and the cut-off point for depth of invasion was set at $4 \mathrm{~mm}$ (low $<4 \mathrm{~mm}$; high $\geq 4 \mathrm{~mm}$ ), as preconized by Almangush et al. ${ }^{24}$ After grading, tumors were divided as follows: low risk (tumor with $<4 \mathrm{~mm}$ depth of invasion and $<5$ buds at the invasive front); intermediate risk (tumor with $\geq 4 \mathrm{~mm}$ depth of invasion and $<5$ buds at the invasive front or superficial tumor $<4 \mathrm{~mm}$, but with $\geq 5$ buds), and high risk (tumor with $\geq 4 \mathrm{~mm}$ depth of invasion and $\geq 5$ buds at the invasive front).

\section{Immunohistochemical analysis}

For immunohistochemistry, $3-\mu \mathrm{m}$ histological sections were mounted on slides prepared with organosilane adhesive (3-aminopropyltriethoxysilane, Sigma Chemical Co., St. Louis, USA) and submitted to immunoperoxidase staining using primary anti-XPF (Clone 219; dilution: 1:800; Lab Vision Corporation, Freemont, USA) and anti-XRCC1 (Clone 33-2-5; dilution: 1:2,000; Lab Vision Corporation, Freemont, USA) antibodies. The sections were incubated overnight with the primary antibodies diluted in Diamond solution (Cell Marque, Rocklin, USA). Positive and negative controls were established according to manufacturer specifications.

Cells exhibiting brown staining in the nucleus and/or cytoplasm regardless of staining intensity were defined as positive. The immunohistochemical staining of the proteins was analyzed semiquantitatively at the tumor invasion front by a single previously calibrated examiner who was unaware of the clinical data. The criteria established by Huang et al. ${ }^{25}$ were followed and the cases were classified as: 0 ( $\leq 10 \%$ immunostained cells), 1 ( $11 \%$ to $50 \%$ immunostained cells), and 2 (> 50\% immunostained cells). For statistical analysis, the cases were stratified into low ( $\leq 50 \%$ immunostained cells) and high (> 50\% immunostained cells) expression as proposed by Seiwert et al. ${ }^{17}$

\section{Statistical analysis}

The results were analyzed statistically using the Statistical Package for the Social Sciences (version 25.0; SPSS, Inc., Chicago, USA). First, descriptive analysis of the data was performed. Statistical tests were then applied to investigate possible associations of the immunoexpression of XPF and XRCC1 with the clinical parameters and histological grade of the OTSCC and LLSCC cases using the chi-squared test or Fisher's exact test, when appropriate.

The immunohistochemical data were analyzed by the Kolmogorov-Smirnov test for normality, which revealed the absence of a normal distribution. Thus, Spearman's correlation test was applied to determine possible correlations between the immunoexpression scores of the proteins. A level 
of significance of $5 \%(p<0.05)$ was adopted for all tests.

\section{Results}

\section{Clinicopathological analysis}

The clinicopathological characteristics of the selected cases are shown in Table 1 . The age of the patients ranged from 25 to 92 years (mean 60.5 years). Factors associated with carcinogenesis such as use of tobacco and alcohol and sun exposure were evaluated. Among the patients with OTSCC, $72.5 \%(\mathrm{n}=29)$ were smokers and 55\% $(\mathrm{n}=22)$ alcohol drinkers. Among the patients with LLSCC, $82.5 \%$ had a history of chronic sun exposure, $77.5 \%(n=31)$ were smokers, and $30 \%$ were alcohol drinkers. With respect to TNM stage, stage III was found in $42 \%$ of the OTSCC cases and stage II predominated in the LLSCC cases (55\%). A combination of three therapeutic modalities (surgical excision, radiotherapy, and chemotherapy) was the most common treatment in the OTSCC cases, corresponding to $42.5 \%$, followed by surgical resection combined with neck dissection (37.5\%). In patients with LLSCC, surgical resection alone was used in $50 \%$ of the cases and was combined with neck dissection in $20 \%$.

More than half the patients with OTSCC (65\%) exhibited complete remission of the tumor, while remission was observed in $90 \%$ of the LLSCC cases. Death due to the tumor was reported for $35 \%$ of the patients with OTSCC and for $10 \%$ of those with LLSCC.

Morphological analysis using the model proposed by Brandwein-Gensler et al. ${ }^{23}$ classified $55 \%$ of the LLSCC cases and 55\% of the OTSCC cases as intermediate-risk carcinomas, while $35 \%$ of the OTSCC cases and $12.5 \%$ of the LLSCC cases were classified as high risk. According to the system proposed by Almangush et al., ${ }^{24}$ a tumor depth $>4 \mathrm{~mm}$ was observed in $75 \%$ of the OTSCC cases and in $65 \%$ of the LLSCC cases. Evaluation of tumor budding identified $\geq 5$ buds in 62.5 and $45 \%$ of the OTSCC and LLSCC cases, respectively. Most OTSCC cases (52.5\%) were classified as high risk and most LLSCC cases (50\%) as intermediate risk.

\section{Immunohistochemical analysis}

High nuclear expression of XPF was observed in $72.5 \%$ of OTSCC. A similar finding was obtained for LLSCC. However, cytoplasmic immunoexpression of XPF was high in OTSCC (95\%), but low in LLSCC (52.5\%) (Figure A-B). No significant associations between $\mathrm{XPF}$ protein expression and the clinicopathological parameters were observed at either anatomical site $(p>0.05)$.

Immunoexpression of protein XRCC1 was only detected in the nucleus and was high in both OTSCC and LLSCC (Figure C-D). Statistically significant associations were found between high nuclear expression of XRCC1 and the absence of regional lymph node metastasis in patients diagnosed with OTSCC $(p=0.006)$ (Table 2). However, nuclear immunoexpression of XRCC1 was not significantly associated with clinical stage $(p=0.101)$, outcome $(p=0.685)$, or recurrence $(p=0.263)$. Regarding tumor size, high nuclear expression was observed in OTSCC categorized as $\mathrm{T} 1(88.9 \%)$ and lower expression levels in tumors categorized as T2-T4 (51.6\%).

High nuclear expression of XRCC1 was observed in $71.4 \%$ of LLSCC cases classified as advanced clinical stage (III-IV). There was no difference in immunostaining intensity between tumors of different sizes. No association was found between the nuclear expression of XRCC1 and lymph node metastasis. High nuclear expression was observed in patients who died (75\%).

No associations were found between XRCC1 expression and the grading systems proposed by Brandwein-Gensler et al. ${ }^{23}(p=1.00)$ or Almangush et $a .^{24}(p>0.05)$, nor when the morphological parameters were analyzed separately ( $p>0.05)$. Tables 2 and 3 show the results of XRCC1 and XPF expression according to clinical parameter and histological grade of malignancy in the cases diagnosed as OTSCC and LLSCC.

\section{Correlation between the immunoexpression of XRCC1 and XPF in OTSCC and LLSCC}

No statistically significant correlation was found between the nuclear immunoexpression of XRCC1 and XPF in cases of OTSCC $(r=0.141 ; p=0.386)$. 
Table 1. Descriptive analysis of socio-demographic and clinical variables of the oral tongue squamous cell carcinoma (OTSCC) and lower lip squamous cell carcinoma (LLSCC) patients.

\begin{tabular}{|c|c|c|}
\hline \multirow{3}{*}{ Parameters } & \multicolumn{2}{|c|}{ Location } \\
\hline & OTSCC $(n=40)$ & $\operatorname{LLSCC}(n=40)$ \\
\hline & n (\%) & $n(\%)$ \\
\hline \multicolumn{3}{|l|}{ Gender } \\
\hline Male & $27(67.5)$ & $30(75.0)$ \\
\hline Female & 13 (32.5) & $10(25.0)$ \\
\hline Age & $60.55 \pm 13.95$ & \\
\hline \multicolumn{3}{|l|}{ Tobacco use } \\
\hline Ever & $29(72.5)$ & $31(77.5)$ \\
\hline Never & $7(17.5)$ & $1(2.5)$ \\
\hline $\mathrm{NI}$ & $4(10.0)$ & $8(20.0)$ \\
\hline \multicolumn{3}{|c|}{ Alcohol drinking use } \\
\hline Ever & $22(55.0)$ & $12(30.0)$ \\
\hline Never & $18(45.0)$ & $7(17.5)$ \\
\hline $\mathrm{NI}$ & - & $21(52.5)$ \\
\hline \multicolumn{3}{|c|}{ Chronic solar exposure } \\
\hline Ever & - & 33 (82.5) \\
\hline Never & - & $0(0.0)$ \\
\hline $\mathrm{NI}$ & - & 7 (17.5) \\
\hline \multicolumn{3}{|l|}{ Tumor size } \\
\hline $\mathrm{T1}$ & $9(22.5)$ & $8(20.0)$ \\
\hline $\mathrm{T} 2$ & $16(40.0)$ & $28(70.0)$ \\
\hline Т3 & $12(30.0)$ & $2(5.0)$ \\
\hline $\mathrm{T} 4$ & $3(7.5)$ & $2(5.0)$ \\
\hline \multicolumn{3}{|l|}{ Node } \\
\hline No & $23(57.5)$ & $30(75.0)$ \\
\hline N1 & $8(20.0)$ & $7(17.5)$ \\
\hline N2 & $9(22.5)$ & $1(2.5)$ \\
\hline N3 & $0(0.0)$ & $2(5.0)$ \\
\hline \multicolumn{3}{|l|}{ Metastasis } \\
\hline MO & $40(100.0)$ & 38 (95.0) \\
\hline M1 & $0(0.0)$ & $2(5.0)$ \\
\hline \multicolumn{3}{|l|}{ Clinical stage } \\
\hline Stage I & $7(17.5)$ & $4(10.0)$ \\
\hline Stage II & $8(20.0)$ & $22(55.0)$ \\
\hline Stage III & $17(42.5)$ & $8(20.0)$ \\
\hline Stage IV & $8(20.0)$ & $6(15.0)$ \\
\hline \multicolumn{3}{|l|}{ Treatment } \\
\hline Surgery & $8(20.0)$ & $20(50.0)$ \\
\hline Surgery + ND & 15 (37.5) & $8(20.0)$ \\
\hline
\end{tabular}

Continue... 


\begin{tabular}{|c|c|c|}
\hline \multicolumn{3}{|l|}{ Continuation } \\
\hline Surgery + RT or ND + ChT & $0(0.0)$ & $2(5.0)$ \\
\hline Surgery + RT + ND & $0(0.0)$ & $4(10.0)$ \\
\hline Surgery + RT + ChT & $17(42.5)$ & $0(0.0)$ \\
\hline $\mathrm{NI}$ & $0(0.0)$ & $6(15.0)$ \\
\hline \multicolumn{3}{|l|}{ Local recurrence } \\
\hline No & $30(75.0)$ & $36(90.0)$ \\
\hline Yes & $10(25.0)$ & $4(10.0)$ \\
\hline \multicolumn{3}{|l|}{ Survival status } \\
\hline Alive at the end period of the study & $26(65.0)$ & $36(90.0)$ \\
\hline Death due to tumor & $14(35.0)$ & $4(10.0)$ \\
\hline
\end{tabular}

$\mathrm{NI}$ : not informed; ND: neck dissection; RT: radiotherapy; ChT: chemotherapy.
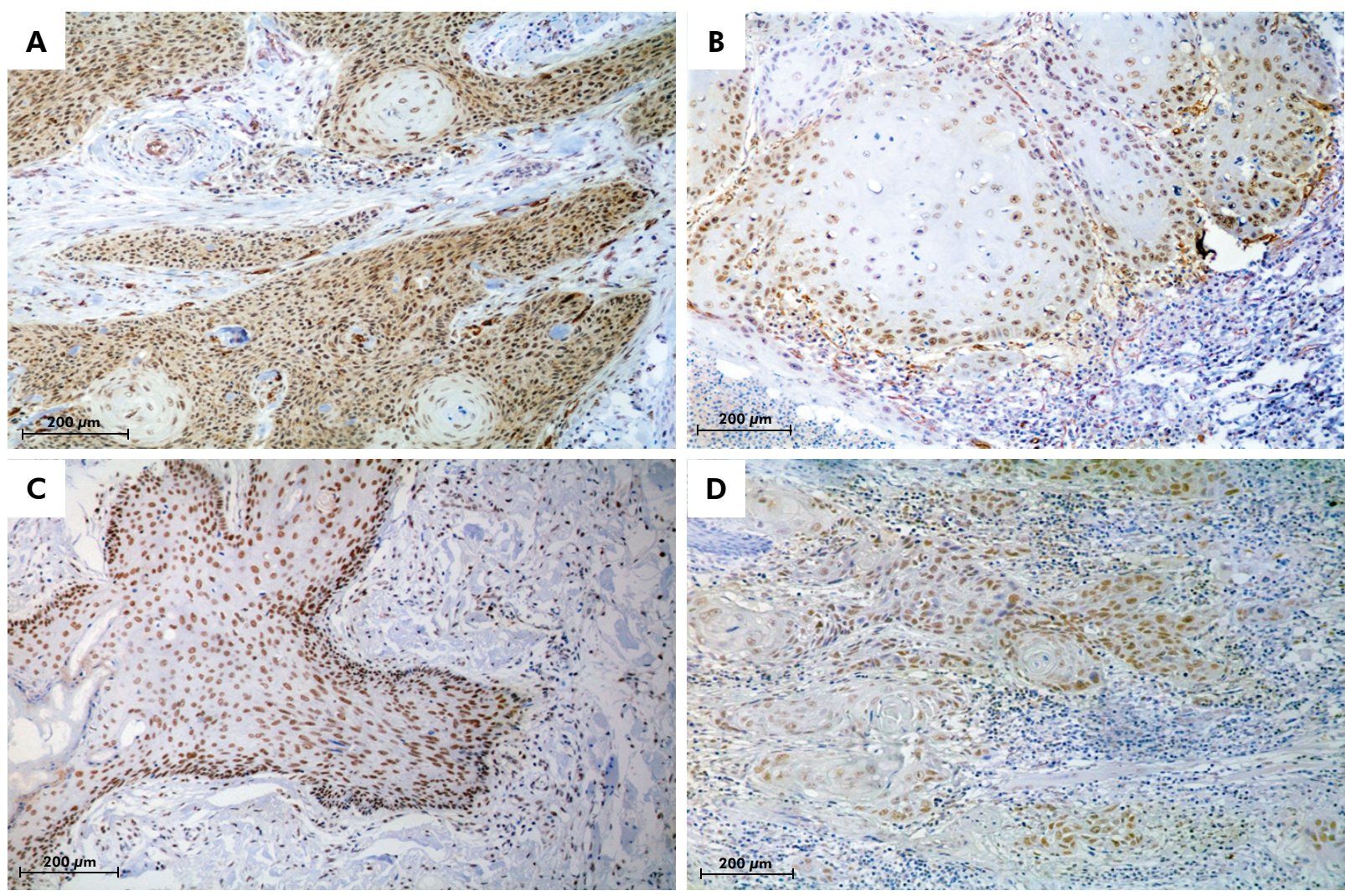

Figure. A. Immunoexpression of XPF protein at the tumor invasion front of lower lip squamous cell carcinoma (LLSCC): positive immunoexpression in the nucleus and cytoplasm of more than $50 \%$ of cells. B. Immunoexpression of XPF protein at the tumor invasion front of oral tongue squamous cell carcinoma (OTSCC): positive immunoexpression in 11 to $50 \%$ of cells. C. Immunoexpression of XRCC 1 protein at the tumor invasion front of LLSCC: positive immunoexpression in 11 to $50 \%$ of cells. D. Immunoexpression of XRCC 1 protein at the tumor invasion front of OTSCC: positive immunoexpression only in the nucleus of more than $50 \%$ of cells.

In LLSCC, Spearman's correlation test revealed a significant and strong positive correlation between the nuclear immunoexpression of XRCC1 and XPF $(r=0.728 ; p<0.0001)$ (Table 4). Since there was no variation in the cytoplasmic expression of XRCC1 in OTSCC or LLSCC, it was not possible to calculate the correlation between the cytoplasmic expression of XRCC1 and XPF in these tumors (Table 4). 
Table 2. XRCC1 and XPF nuclear expression in relation to clinicopathological findings of oral tongue squamous cell carcinoma.

\begin{tabular}{|c|c|c|c|c|c|c|c|c|}
\hline \multirow{2}{*}{ Parameters } & \multicolumn{4}{|c|}{ XRCCI (nuclear) } & \multicolumn{4}{|c|}{ XPF (nuclear) } \\
\hline & Low & High & Total & $\mathrm{p}$-value & Low & High & Total & $\mathrm{p}$-value \\
\hline \multicolumn{9}{|l|}{ Tumor size } \\
\hline $\mathrm{T} 1$ & $1(11.1)$ & 8 (88.9) & $9(100.0)$ & $0.061^{* *}$ & $1(11.1)$ & 8 (88.9) & $9(100.0)$ & $0.399^{* *}$ \\
\hline T2-T4 & $15(48.4)$ & $16(51.6)$ & 31 (100.0) & & $10(32.3)$ & $21(67.7)$ & 31 (100.0) & \\
\hline \multicolumn{9}{|l|}{ Node status } \\
\hline NO & $5(21.7)$ & 18 (78.3) & $23(100.0)$ & $0.006^{*}$ & $4(17.4)$ & 19 (82.6) & $23(100.0)$ & $0.153^{* *}$ \\
\hline $\mathrm{N}+$ & 11 (64.7) & 6 (35.3) & 17 (100.0) & & 7 (41.2) & 10 (58.8) & 17 (100.0) & \\
\hline \multicolumn{9}{|l|}{ Clinical stage } \\
\hline$|-| \mid$ & $3(21.4)$ & 11 (78.6) & 14 (100.0) & $0.101^{* *}$ & $3(21.4)$ & 11 (78.6) & 14 (100.0) & $0.715^{* *}$ \\
\hline III-IV & $13(50.0)$ & $13(50.0)$ & $26(100.0)$ & & $8(30.8)$ & 18 (69.2) & $26(100.0)$ & \\
\hline \multicolumn{9}{|l|}{ Survival status } \\
\hline Alive at the end period of the study & $11(42.3)$ & $15(57.7)$ & $26(100.0)$ & $0.685^{*}$ & $8(30.8)$ & $18(69.2)$ & $26(100.0)$ & $0.715^{* *}$ \\
\hline Death due to tumor & $5(35.7)$ & 9 (64.3) & $14(100.0)$ & & $3(21.4)$ & $11(76.8)$ & $14(100.0)$ & \\
\hline \multicolumn{9}{|l|}{ Recurrence } \\
\hline Yes & $2(20.0)$ & $8(80.0)$ & $10(100.0)$ & $0.263^{* *}$ & $2(20.0)$ & $8(80.0)$ & $10(100.0)$ & $0.696^{* *}$ \\
\hline No & $14(46.7)$ & $16(53.3)$ & $30(100.0)$ & & $19(30.0)$ & $21(70.0)$ & $30(100.0)$ & \\
\hline \multicolumn{9}{|l|}{ Brandwein Gensler et al. (2005) } \\
\hline LR-IR & $10(38.5)$ & $16(61.5)$ & $26(100.0)$ & $0.787^{*}$ & $8(30.8)$ & $18(69.2)$ & $26(100.0)$ & $0.715^{* *}$ \\
\hline $\mathrm{HR}$ & $6(42.9)$ & $8(57.1)$ & $14(100.0)$ & & $3(21.4)$ & $11(78.6)$ & $14(100.0)$ & \\
\hline \multicolumn{9}{|l|}{ Almangush et al. (2015) } \\
\hline Score 0 & $6(31.6)$ & $13(68.4)$ & 19 (100.0) & $0,301^{*}$ & $7(36.8)$ & $12(63.2)$ & $19(100.0)$ & $0.293^{* *}$ \\
\hline Scores $1-2$ & $10(47.6)$ & 11 (52.4) & 21 (100.0) & & 4 (19.0) & 17 (81.0) & $21(100.0)$ & \\
\hline
\end{tabular}

LR: low risk; IR: intermediate risk; HR: high risk; ${ }^{*} \chi 2$ test; ${ }^{* *}$ Fisher's exact test.

\section{Discussion}

The cellular DNA is frequently damaged to different extents by endogenous and exogenous mutagenic agents. ${ }^{13,26}$ Once damaged, the DNA can elicit through certain molecules responses ranging from the induction of cell apoptosis to growth deregulation, which can lead to conditions associated with genome instability such as cancer. ${ }^{27}$ The genes that encode these molecules involved in the repair of DNA damage have been studied as biological markers of cancer and might be associated with tumor development and patient prognosis. . $^{14,28,29}$

OTSCC is frequently diagnosed in an advanced clinical stage and is associated with high rates of morbidity and mortality when compared to LLSCC. ${ }^{30}$
Given the heterogeneity of head and neck cancers and their biological behavior and etiological factors, it is important to evaluate markers associated with DNA repair in SCC arising from different anatomical sites.

Major etiological and predisposing factors for oral SCC include mostly smoking and drinking habits, and ultraviolet radiation (specifically for LLSCC). Cigarette smoking may induce different types of DNA damage including adducts, strand breaks, and cross-links, which are repaired through different DNA repair pathways. ${ }^{13}$ In addition, both UVA and UVB radiation is proven to produce DNA damage directly and indirectly through oxidative stress, promoting mutation in key genes associated with cell proliferation, DNA repair, and / or apoptotic cell death. ${ }^{31}$ 
Immunohistochemical expression of DNA repair proteins in oral tongue and lower lip squamous cell carcinoma

Table 3. XRCC1 and XPF nuclear expression in relation to clinicopathological findings of lower lip squamous cell carcinoma.

\begin{tabular}{|c|c|c|c|c|c|c|c|c|}
\hline \multirow{2}{*}{ Parameters } & \multicolumn{4}{|c|}{ XRCCI (nuclear) } & \multicolumn{4}{|c|}{ XPF (nuclear) } \\
\hline & Low & High & Total & $p$-value & Low & High & Total & $p$-value \\
\hline \multicolumn{9}{|l|}{ Tumor size } \\
\hline $\mathrm{T} 1$ & $3(37.5)$ & $5(62.5)$ & 8 (100.0) & $1.000^{* *}$ & $2(25.0)$ & $6(75.0)$ & 8 (100.0) & $1.000^{* *}$ \\
\hline T2-T4 & $10(31.2)$ & $22(68.8)$ & $32(100.0)$ & & $10(31.2)$ & $22(68.8)$ & 32 (100.0) & \\
\hline \multicolumn{9}{|l|}{ Node status } \\
\hline NO & $9(30.0)$ & $21(70.0)$ & $30(100.0)$ & $0.700^{* *}$ & $8(26.7)$ & $22(73.3)$ & 30 (100.0) & $0.451^{* *}$ \\
\hline $\mathrm{N}+$ & $4(40.0)$ & $6(60.0)$ & $10(100.0)$ & & $4(40.0)$ & $6(60.0)$ & 10 (100.0) & \\
\hline \multicolumn{9}{|l|}{ Clinical stage } \\
\hline I-II & 9 (34.6) & $17(65.4)$ & $26(100.0)$ & $1.000^{* *}$ & $8(30.8)$ & 18 (69.2) & $26(100.0)$ & $1.000^{* *}$ \\
\hline III-IV & $4(28.6)$ & $10(71.4)$ & $14(100.0)$ & & $4(28.6)$ & 10 (71.4) & $14(100.0)$ & \\
\hline \multicolumn{9}{|l|}{ Survival status } \\
\hline Alive at the end period of the study & $12(33.3)$ & $24(66.7)$ & $36(100.0)$ & $1.000^{* *}$ & $11(30.6)$ & $25(69.4)$ & $36(100.0)$ & $1.000^{* *}$ \\
\hline Death due to tumor & $1(25.0)$ & $3(75.0)$ & $4(100.0)$ & & $1(25.0)$ & $3(75.0)$ & $4(100.0)$ & \\
\hline \multicolumn{9}{|l|}{ Recurrence } \\
\hline Yes & $0(0.0)$ & $4(100.0)$ & $4(100.0)$ & $0.284^{* *}$ & $0(0.0)$ & $4(100.0)$ & $4(100.0)$ & $0.297^{* *}$ \\
\hline No & $13(36.1)$ & $23(63.9)$ & $36(100.0)$ & & $12(33.3)$ & $24(66.7)$ & $36(100.0)$ & \\
\hline \multicolumn{9}{|l|}{ Brandwein Gensler et al. (2005) } \\
\hline$L R-I R$ & $12(34.3)$ & $23(65.7)$ & $35(100.0)$ & $1.000^{* *}$ & $11(31.4)$ & $24(68.6)$ & $35(100.0)$ & $1.000^{* *}$ \\
\hline $\mathrm{HR}$ & $1(20.0)$ & $4(80.0)$ & $5(100.0)$ & & $1(20.0)$ & $4(80.0)$ & $5(100.0)$ & \\
\hline \multicolumn{9}{|l|}{ Almangush et al. (2015) } \\
\hline Score 0 & 11 (39.3) & $17(60.7)$ & $28(100.0)$ & $0.271^{* *}$ & $10(35.7)$ & 18 (64.3) & $28(100.0)$ & $0.285^{* *}$ \\
\hline Scores $1-2$ & $2(16.7)$ & 10 (83.3) & $12(100.0)$ & & $2(16.7)$ & 10 (83.3) & 12 (100.0) & \\
\hline
\end{tabular}

LR: low risk; IR: intermediate risk; HR: high risk; ${ }^{*} \chi 2$ test; ${ }^{* *}$ Fisher's exact test.

Table 4. Correlation between XRCC1 and XPF immunoexpression.*

\begin{tabular}{lcc}
\hline XRCC1/XPF (nuclear) & $r$ & $p$-value \\
\hline OTSCC & 0.235 & 0.145 \\
LLSCC & 0.728 & $<0.0001$ \\
\hline
\end{tabular}

*Spearman's correlation test. LLSCC: lower lip squamous cell carcinoma; OTSCC: oral tongue squamous cell carcinoma.

DNA damage is associated with an increased risk of cancer, in which the reduced capacity of DNA repair can accelerate changes and mutations in essential genes, triggering carcinogenesis. ${ }^{13,20,29}$ In this study, we observed a significant difference in the cytoplasmic protein expression of XPF between the OTSCC and LLSCC groups, with higher expression in OTSCC cases; however, there was no association with the clinical parameters analyzed. This cytoplasmic expression of XPF may indicate deregulation of protein function in OTSCC, which could contribute to the more aggressive behavior of the tumor at this anatomical site.

Our results disagree with Vaezi et $a .^{22}$ and Seiwert et al. ${ }^{17}$ who demonstrated a significant association between high XPF expression and poor clinical outcome in patients with head and neck SCC. On the other hand, consistent with our results, the recent study by Prochnow et al. ${ }^{32}$ found no association between the expression of XPF and clinical stage or prognosis in the cases analyzed.

Several studies suggest that the expression of XPF and XCRR1 can influence the prognosis in cases treated with DNA-damaging agents because of the 
association of these drugs with the chemoresistance of neoplastic cells. ${ }^{25,33,34}$ Like XRCC1, XPF plays an important role in the DNA repair pathways, particularly nucleotide excision repair. This pathway is used by the neoplastic process to correct the damage caused by the genotoxicity of platinum compounds and radiation. Studies using cells from XPF-deficient patients and animal models have shown that low expression of XPF is associated with higher sensitivity to DNA-damaging agents. ${ }^{21,29}$

Ang et al. ${ }^{21}$ observed high nuclear expression of protein XRCC1 in head and neck carcinomas, which was related to poor patient survival, especially among those undergoing chemotherapy. In the study of Mahjabeen et al., ${ }^{14}$ expression of XRCC1 was associated with poor survival in a series of head and neck carcinomas and immunostaining for the protein was observed in both cytoplasm and nucleus. The authors reported cytoplasmic staining to be associated with a mutation in the gene and suggested that the deregulation of DNA repair genes such as XRCC1, APEX1, and OGG1, combined with high Ki67 expression, contributes to the progression of head and neck carcinomas. In our study, there was no cytoplasmic expression of XRCC1 in OTSCC, but high nuclear expression was associated with the absence of loco-regional metastasis, suggesting the use of high nuclear staining and absent cytoplasmic expression as a favorable prognostic marker in patients with OTSCC. Further studies are necessary to confirm these findings.

In previous studies investigating the expression of XRCC1 in tumors diagnosed at different anatomical sites such as those of Sultana et al. ${ }^{35}$ in breast cancer and Liu et al. ${ }^{36}$ in clear cell renal cell carcinoma, low expression of this protein was associated with more aggressive tumors, more advanced stages, higher rates of lymph node metastases, and poor survival. The authors concluded that deficient XRCC1 expression can be used as a prognostic biomarker for these carcinomas.

Regarding the immunoexpression of XPF, Vaezi et al. ${ }^{22}$ showed that high expression of this protein is associated with tumor progression. The authors found a better clinical outcome for tumors that expressed low levels of XPF. Seiwert et al. ${ }^{17}$ analyzed the expression of XPF in head and neck carcinoma and concluded that expression of this protein varies among carcinomas at different sites. We observed higher expression of XPF in cases diagnosed as OTSCC compared to the sample of LLSCC. This is the first study that evaluated immunostaining of the DNA repair proteins XPF and XRCC1 in LLSCC and it is possible that the two proteins act differently in LLSCC due to the peculiarities of this tumor when compared to OTSCC, especially in terms of the etiological factor. Applebaum et al. ${ }^{37}$ observed a higher frequency of the XRCC1 gene polymorphism in smoking patients and suggested that this polymorphism may confer susceptibility to head and neck SCC in smokers. However, there are no studies evaluating the effect of solar radiation on polymorphisms in DNA repair proteins.

In conclusion, by affecting genomic stability, the deregulation of DNA repair proteins may be associated with the development and progression of SCC. Therefore, studies using different techniques are needed to identify the association between the proteins analyzed and the development, progression, and prognosis of SCC at different anatomical sites according to their peculiarities. Our study indicated an association between high nuclear expression of $\mathrm{XRCC} 1$ and the absence of loco-regional metastasis in OTSCC cases, suggesting that this protein is an important prognostic marker of this tumor. We also observed differences in the expression pattern of XPF between the anatomical sites analyzed; however, the expression of this protein was not significantly associated with the clinical course of LLSCC or OTSCC. Finally, immunohistochemical analysis of these proteins can be auxiliary to the methods of evaluation of staging and histological classification of the tumor to analyze the behavior of the tumor.

\section{Acknowledgment}

This study was supported by Postgraduate Program in Oral Pathology of the UFRN and Coordination for the Improvement of Higher Education Personnel - CAPES. $\mathrm{RAF}$ is a research fellow at CNPq. 
- Immunohistochemical expression of DNA repair proteins in oral tongue and lower lip squamous cell carcinoma

\section{References}

1. Jemal A, Bray F, Center MM, Ferlay J, Ward E, Forman D. Global cancer statistics. CA Cancer J Clin. 2011 Mar-Apr;61(2):69-90. https://doi.org/doi.org/10.3322/caac.20107

2. Wang Y, Chen S, Ni Y, Magee D, Pu Y, Zhou Q, et al. Three-dimensional reconstruction with serial whole-mount sections of oral tongue squamous cell carcinoma: A preliminary study. J Oral Pathol Med. 2018 Jan;47(1):53-9. https://doi.org/doi.org/10.1111/jop.12644

3. Santana T, Sá MC, de Moura Santos E, Galvão HC, Coletta RD, Freitas RA. DNA base excision repair proteins APE-1 and XRCC-1 are overexpressed in oral tongue squamous cell carcinoma. J Oral Pathol Med. 2017 Aug;46(7):496-503. https://doi.org/10.1111/jop.12529

4. Gueiros LA, Coletta RD, Kowalski LP, Lopes MA. Clinicopathological features and proliferation markers in tongue squamous cell carcinomas. Int J Oral Maxillofac Surg. 2011 May;40(5):510-5. https://doi.org/10.1016/i.ijom.2010.12.008

5. Blanchard P, Belkhir F, Temam S, El Khoury C, De Felice F, Casiraghi O, et al. Outcomes and prognostic factors for squamous cell carcinoma of the oral tongue in young adults: a single-institution case-matched analysis. Eur Arch Otorhinolaryngol. 2017 Mar;274(3):1683-90. https://doi.org/10.1007/s00405-016-4419-1

6. Morais EF, Santos HB, Cavalcante IL, Rabenhorst SH, Dos Santos JN, Galvão HC, et al. Twist and E-cadherin deregulation might predict poor prognosis in lower lip squamous cell carcinoma. Oral Surg Oral Med Oral Pathol Oral Radiol. 2019 Apr;127(4):318-29. https://doi.org/10.1016/i.0000.2018.11.003

7. Ozkul Y, Songu M, Imre A, Tunc E, Ozkul Z, Arslanoglu S, et al. Early stage squamous cell carcinoma of the lower lip: predictive factors for recurrence. J Laryngol Otol. 2016 Apr;130(4):369-72. https://doi.org/10.1017/S0022215116000311

8. Rivera C, Oliveira AK, Costa RA, De Rossi T, Leme AFP. Prognostic biomarkers in oral squamous cell carcinoma: a systematic review. Oral Oncol. 2017 Sep;72:38-47. https://doi.org/10.1016/i.oraloncology.2017.07.003

9. Gaba Fl, Sheth CC, Veses V. Salivary biomarkers and their efficacies as diagnostic tools for Oral Squamous Cell Carcinoma: systematic review and meta-analysis. J Oral Pathol Med. 2018 Oct; [Preprint]. https://doi.org/10.1111/jop.12791

10. Chi AC, Day TA, Neville BW. Oral cavity and oropharyngeal squamous cell carcinoma: an update. CA Cancer J Clin. 2015 Sep-Oct;65(5):401-21. https://doi.org/10.3322/caac.21293

11. Bajpai D, Banerjee A, Pathak S, Jain SK, Singh N. Decreased expression of DNA repair genes (XRCC1, ERCC1, ERCC2, and ERCC4) in squamous intraepithelial lesion and invasive squamous cell carcinoma of the cervix. Mol Cell Biochem. 2013 May;377(1-2):45-53. https://doi.org/10.1007/s11010-013-1569-y

12. London RE. The structural basis of XRCC1-mediated DNA repair. DNA Repair (Amst). 2015 Jun;30:90-103. https://doi.org/10.1016/i.dnarep.2015.02.005

13. Avci H, Ergen A, Bireller ES, Ertugrul B, Cakmakoglu B. A strong relationship between oral squamous cell carcinoma and DNA repair genes. Biochem Genet. 2017 Dec;55(5-6):378-86. https://doi.org/10.1007/s10528-017-9806-9

14. Mahjabeen I, Ali K, Zhou X, Kayani MA. Deregulation of base excision repair gene expression and enhanced proliferation in head and neck squamous cell carcinoma. Tumour Biol. 2014 Jun;35(6):5971-83. https://doi.org/10.1007/s13277-014-1792-5

15. Nickson CM, Moori P, Carter RJ, Rubbi CP, Parsons JL. Misregulation of DNA damage repair pathways in HPV-positive head and neck squamous cell carcinoma contributes to cellular radiosensitivity. Oncotarget. 2017 May;8(18):29963-75. https://doi.org/10.18632/oncotarget.16265

16. Huang X, Liv C, Cui Y, Zhang H, Liu Y, Zhou X, et al. Association between XRCCl and ERCCl single-nucleotide polymorphisms and the efficacy of concurrent radiochemotherapy in patients with esophageal squamous cell carcinoma. Oncol Lett. 2017 Feb;13(2):704-14. https://doi.org/10.3892/ol.2016.5496

17. Seiwert TY, Wang X, Heitmann J, Villegas-Bergazzi V, Sprott K, Finn S, et al. DNA repair biomarkers XPF and phosphoMAPKAP kinase 2 correlate with clinical outcome in advanced head and neck cancer. PLoS One. 2014 Jul;9(7):e102112. https://doi.org/10.1371/journal.pone.0102112

18. Sá MC, Conceição TS, Santos EM, Morais EF, Galvão HC, Freitas RA. Immunohistochemical expression of TFIIH and XPF in oral tongue squamous cell carcinoma. Eur Arch Otorhinolaryngol. 2020 Mar;277(3):893-902. https://doi.org/10.1007/s00405-019-05757-2

19. Zhao XN, Usdin K. The repeat expansion diseases: the dark side of DNA repair? DNA Repair (Amst). 2015 Aug; 32:96-105. https://doi.org/10.1016/i.dnarep.2015.04.019

20. Cheng J, Liu W, Zeng X, Zhang B, Guo Y, Qiu M, et al. XRCC3 is a promising target to improve the radiotherapy effect of esophageal squamous cell carcinoma. Cancer Sci. 2015 Dec;106(12):1678-86. https://doi.org/10.1111/cas.12820

21. Ang MK, Patel MR, Yin XY, Sundaram S, Fritchie K, Zhao N, et al. High XRCCl protein expression is associated with poorer survival in patients with head and neck squamous cell carcinoma. Clin Cancer Res. 2011 Oct;17(20):6542-52. https://doi.org/10.1158/1078-0432.CCR-10-1604 
22. Vaezi A, Wang X, Buch S, Gooding W, Wang L, Seethala RR, et al. XPF expression correlates with clinical outcome in squamous cell carcinoma of the head and neck. Clin Cancer Res. 2011 Aug;17(16):5513-22. https://doi.org/10.1158/1078-0432.CCR-11-0086

23. Brandwein-Gensler M, Teixeira MS, Lewis CM, Lee B, Rolnitzky L, Hille JJ, et al. Oral squamous cell carcinoma: histologic risk assessment, but not margin status, is strongly predictive of local disease-free and overall survival. Am J Surg Pathol. 2005 Feb;29(2):167-78. https://doi.org/10.1097/01.pas.0000149687.90710.21

24. Almangush A, Coletta RD, Bello IO, Bitu C, Keski-Säntti H, Mäkinen LK, et al. A simple novel prognostic model for early stage oral tongue cancer. Int J Oral Maxillofac Surg. 2015 Feb;44(2):143-50. https://doi.org/10.1016/j.ijom.2014.10.004

25. Huang MY, Tsai HL, Lin CH, Huang CW, Ma CJ, Huang CM, et al. Predictive value of ERCC1, ERCC2, and XRCC1 overexpression for stage III colorectal cancer patients receiving FOLFOX-4 adjuvant chemotherapy. J Surg Oncol. 2013 Dec;108(7):457-64. https://doi.org/10.1002/jso.23422

26. Yang $\mathrm{CH}$, Lin YD, Yen CY, Chuang LY, Chang HW. A systematic gene-gene and gene-environment interaction analysis of DNA repair genes XRCC1, XRCC2, XRCC3, XRCC4, and oral cancer risk. OMICS. 2015 Apr;19(4):238-47. https://doi.org/10.1089/omi.2014.0121

27. Putthanachote N, Promthet S, Hurst $C$, Suwanrungruang K, Chopiitt $P$, Wiangnon $S$, et al. The XRCC 1 DNA repair gene modifies the environmental risk of stomach cancer: a hospital-based matched case-control study. BMC Cancer. 2017 Oct;17(1):680. https://doi.org/10.1186/s12885-017-3675-9

28. Wang W, Han S, Yao Z, Li X, Huang P, Zhang M, et al. A study of epidemiologic and recurrence factors of oral cancer. J Oral Maxillofac Surg. 2012 Sep;70(9):2205-10. https://doi.org/10.1016/i.joms.2011.09.040

29. Carron J, Lopes-Aguiar L, Costa EF, Nogueira GA, Lima TR, Pincinato EC, et al. GSTP1 c.313A>G, XPD c.934G>A, XPF c.2505T>C and CASP9 c.-1339A>G Polymorphisms and severity of vomiting in head and neck cancer patients treated with cisplatin chemoradiation. Basic Clin Pharmacol Toxicol. 2017 Dec;121(6):520-5. https://doi.org/10.1111/bcpt.12842

30. Alaeddini M, Etemad-Moghadam S. Lymphangiogenesis and angiogenesis in oral cavity and lower lip squamous cell carcinoma. Braz J Otorhinolaryngol. 2016 Jul-Aug;82(4):385-90. https://doi.org/10.1016/i.bjorl.2015.06.008

31. Souza LR, Fonseca-Silva T, Pereira CS, Santos EP, Lima LC, Carvalho HA, et al. Immunohistochemical analysis of p53, APE1, hMSH2 and ERCC1 proteins in actinic cheilitis and lip squamous cell carcinoma. Histopathology. 2011 Feb;58(3):352-60. https://doi.org/10.1111/j.1365-2559.2011.03756.x

32. Prochnow S, Wilczak W, Bosch V, Clauditz TS, Muenscher A. ERCC1, XPF and XPA-locoregional differences and prognostic value of DNA repair protein expression in patients with head and neck squamous cell carcinoma. Clin Oral Investig. 2019 Aug;23(8):3319-29. https://doi.org/10.1007/s00784-018-2751-0

33. Köberle B, Ditz C, Kausch I, Wollenberg B, Ferris RL, Albers AE. Metastases of squamous cell carcinoma of the head and neck show increased levels of nucleotide excision repair protein XPF in vivo that correlate with increased chemoresistance ex vivo. Int J Oncol. 2010 May;36(5):1277-84. https://doi.org/10.3892/ijo_00000612

34. Hasegawa Y, Goto M, Hanai N, Ozawa T, Hirakawa H. Predictive biomarkers for combined chemotherapy with 5-fluorouracil and cisplatin in oro- and hypopharyngeal cancers. Mol Clin Oncol. 2018 Feb;8(2):378-86. https://doi.org/10.3892/mco.2017.1521

35. Sultana R, Abdel-Fatah T, Abbotts R, Hawkes C, Albarakati N, Seedhouse C, et al. Targeting XRCC1 deficiency in breast cancer for personalized therapy. Cancer Res. 2013 Mar;73(5):1621-34. https://doi.org/10.1158/0008-5472.CAN-12-2929

36. Liu QH, Wang Y, Yong HM, Hou PF, Pan J, Bai J, et al. XRCC1 serves as a potential prognostic indicator for clear cell renal cell carcinoma and inhibits its invasion and metastasis through suppressing MMP-2 and MMP-9. Oncotarget. 2017 Nov;8(65):109382-92. https://doi.org/10.18632/oncotarget.22680

37. Applebaum KM, McClean MD, Nelson HH, Marsit CJ, Christensen BC, Kelsey KT. Smoking modifies the relationship between XRCC1 haplotypes and HPV16-negative head and neck squamous cell carcinoma. Int J Cancer. 2009 Jun;124(11):2690-6. https://doi.org/10.1002/ijc.24256 